\title{
Intuitive expertise in ICT graduate supervision
}

A Personal Reflection on the Graduate Supervisory Methods used by Professor David Squires in Computers in Education at King's College, London

Jill Jameson
University of Greenwich
email:j.jameson@gre.ac.uk

Intuitive expertise in the application of advanced interdisciplinary facilitation is the subject of this personal reflection on the graduate supervisory style of Professor David Squires in computers in education. This single-case reflective study examines the characteristics of effective supervision observed during masters and doctoral supervision at King's College in the years 1990-9. Interdisciplinarity in ICT graduate studies particularly requires a fluency of supervisory expertise in enabling supervisees to combine multiple complex perspectives from a number of fields of knowledge. Intuitive combinatory aspects of supervision are highlighted in this reflection on the role carried out by an academic expert in facilitating student success. This is examined from a perspective incorporating affective as well as intellectual elements, informed by characteristics identified in professional sports and performing arts coaching/mentoring. Key characteristics comprising a model of intuitive expertise in ICT graduate supervision were outlined. The resultant portrait aims to complement existing literature on graduate supervision, with reference to the field of ICT/computers in education relating to student hypermedia composition.

\section{Foreword}

I learned about David Squires' untimely death on 10 September 2001, when contacting King's to find out why a routine request to him for a reference had gone unanswered. The horror of 11 September will always be, for me, therefore, informed by the sadness that overcame me when I heard that David had passed away. A man of dignity, advanced thought and great kindness, David's contribution to the field of computers in education, and to international education in general, was unique. I am privileged to have had the opportunity to have learned so much from him in a valuable experience of nearly ten years of his excellent graduate teaching and supervision, and will remember well the example of holistic expertise that he set. 


\section{Introduction}

The role of intuitive expertise in ICT graduate education, applied with the kind of fluent and spontaneous 'automaticity' demonstrated by expert coaches in sporting and performing arts (Tan, 1997), is the most significant feature of the model of academic graduate supervisor proposed here. Advanced sports coaches are routinely characterized by an adept, seemingly spontaneous use of applied expertise, a combination of cognitive, affective and mentoring techniques that focus on improving the performance of individual athletes, whose attributes are well understood by them. The seemingly effortless fluency and holistic serendipity of this model of applied expertise is a key point differentiating this concept of the 'coach-mentor' from existing perceptions of graduate ICT academic supervision.

In reviewing recent work (Parsloe and Wray, 2000) on coaching/mentoring in technology use, Hartley (2001) notes the increasing need to support students 'in skills of communication, study methods, creativity, problem-solving and collaborative learning' in a competitive global economic market, and therefore the increased need for an understanding of the role of coaching/mentoring in education. Current governmental aims to widen participation to 50 per cent of the 18-30-year-old population will almost inevitably result in a greater need for effective student support at postgraduate level as higher education expands and widens its intake of students (Ainley, Jameson, Jones, Hall, and Farr, 2002). In preparing for this potential expansion, both the performance aspects of coaching and the personal growth characteristics related to mentoring are therefore important in considering the effectiveness of academic graduate supervision in supporting student success.

In ICT, supervisory fluency in an adept use of coaching/mentoring techniques incorporates not only a thorough understanding and insightful response to individual students, based on practical experience of the real capabilities of the supervisees, but also the balanced awareness of a multidisciplinary perspective. This emphasizes the interdisciplinary role of computers in education. Skilled supervisors are able expertly to facilitate graduate students to incorporate in their work significant elements of other key disciplines, while placing an emphasis on pedagogy in education research rather than technocentric skills acquisition (Papert, 1987).

\section{Interdisciplinarity in graduate ICT in education study}

In some ways, the discipline of ICT in education - and its varying closely related conceptualizations as 'computers in education', 'educational computing' or the much more widely conceived field of 'learning technologies' - is an increasingly mature subject area. Watson (2001) surveys the growth of ICT in schools' curricula in the UK over the past twenty years, noting that almost thirty major hardware and software initiatives have taken place in this time, the numbers of computers in schools consequently rising from around one per school in 1980 to one for every eight pupils by 1998. ICT in education can therefore no longer said to be 'new'.

Routinely viewed in some governmental initiatives as a panacea for reinvigorating outdated teaching methodology, ICT in education, as Watson notes, has been officially hailed - by Heseltine in 1995 and David Blunkett in 2001 - as a revolutionary tool to enhance 'progress' in learning, knowledge acquisition, information skills and economic 
advancement. However, Watson is highly sceptical of what she envisages as the technocentric and confused nature of a generally over-enthusiastic series of directives on the importance of using computers in education. Drawing attention to the familiar dichotomy between ICT as a vocational skills area in its own right, and the use of IT learning technologies as a pedagogic cross-curricular tool, she notes that the conflicts and confusions between these two conceptions of ICT are factors that have sometimes bedevilled the actual take-up of technology by teachers in schools. Watson argues that educational computing, despite its considerable history, has 'yet to find its own voice' as a subject area, and that what is needed is to 're-frame ICT policy within the process of educational debate and change' - that is, to focus on the pedagogical, not merely the technological contributions of ICT in education. This echoes earlier seminal work proposing the key importance of mindful engagement by learners in the use of computers as cognitive tools, rather than more automatic usage of computers for browsing or meaningful skills acquisition (Salomon, Perkins and Globerson, 1991).

If we are to agree with the well-argued and valuable proposition that learning can be enabled by ICT use, but is not mechanistically acquired - either by having advanced technological resources or the routine skills to use them - then putting the 'pedagogy' back into ICT remains a crucial issue. This highlights again its interdisciplinary nature in enabling teaching and learning across the curriculum. The cross-curricular use of IT, or CAL, to use the more familiar term, is the side of Watson's dichotomy that still remains to be significantly more developed. ICT in education studies, notably interactive multimedia studies, has for some years already effectively enabled a fluent incorporation of multidisciplinary perspectives. However, one could agree with Watson's observation that meaningful application of this in teaching is still disappointingly rare.

Although as an enabling tool, learning technology can facilitate the learner to weave together intermingled elements of other disciplines into a rich tapestry that articulates a new language, many teachers - at all levels of education - do not yet speak it very well. Advancements in the incorporation of digital media into 'English', CAD into 'Engineering', e-Commerce in 'Business' are well-known examples of the transformation of subject disciplines by technological IT advances, but such progression does not necessarily lead to more effective learning directly enabled through the use of ICT. As pedagogy, effective usage of ICT in education aims to enhance conceptual development both in the student-computer interaction with technology and in the cognitive benefit derived from the effects of technology. (Salomon et al., 1991).

In the two research projects that were the focus of this personal reflection, the subject of hypermedia research incorporated an eclectic mix of Computers in Education, English Literature and Media Studies, focusing on active hypermedia authoring by students as a design process. Through a 'measurement of stages' methodology capturing successive timebased phases of learners' hypermedia work, the doctoral case study, based on extensive work by a small number of further education female adult learners in 1995-7, drew inductive inferences from overall patterns observed in students' work. Overall, the final study found that students had derived benefits in terms of a 'cognitive residue' of selfempowerment through an expansion in expressive, creative and problem-solving capability enabled in active hypermedia composition (Jameson, 1999). 
The creation of an explanatory model for the hypermedia composition process in novice learners (Jameson and Squires, 1999) and an assessment instrument in the form of a rubric for evaluating student hypermedia composition was the result of the research. An emphasis on process as well as product in hypermedia composition emerged. Stemler (1997) is amongst those who also observe that interactive multimedia is 'a process, rather than a technology, that places new learning potential into the hands of its users'. Hardware and software make this process possible, but ultimately the learner-technology interaction is the key enabler in the assimilation of old - and the making of new - knowledge. As researchers Kahn and Ullah (1997) noted of the Multimedia Makers project, 'the greatest learning involving multimedia actually occurs when students create their own multimedia projects - that is, the learning is in the making'. The distinctions made by Papert between instructionism, constructivism, and constructionism (Papert, 1991), in which the emphasis is on the 'child as builder', are at issue here:

Constructionism - the $\mathrm{N}$ word as opposed to the $\mathrm{V}$ word - shares constructivism's connotation of learning as 'building knowledge structures' irrespective of the circumstances of the learning. It then adds the idea that this happens especially felicitously in a context where the learner is consciously engaged in constructing a public entity, whether it's a sand castle on the beach or a theory of the universe. (Papert, 1991)

The facilitation of graduate students in their own 'making' of research in the learningtechnology interactive process particularly requires a fluency of expertise that, in combining multiple complex perspectives from a variety of disciplines, has elements beyond an existing accumulation of received knowledge. In other words, the effective graduate ICT in education supervisor needs not just to be an expert in advanced knowledge of the field of learning technologies in education, but to be able to facilitate students intuitively to incorporate together previously unknown elements of other disciplines. The facilitation of graduate students making new knowledge in ICT in education requires a degree of advanced combinatory fluency that transcends the application of more singular disciplinary expertise. It also requires a sophisticated and perceptive awareness of student's ability to handle the cross-disciplinary research problems inherent in merging the divide between ICT in education and other specific subject disciplines.

Such a requirement for spontaneous fluency in the application of supervisory skills in ICT in education has some similarities with the demanding work of advanced coaches in the field of physical education, whose dedication to their field can, in some instances, lead to suprisingly good improvements in individual supervisees' performances. In academic learning technologies supervision, a more normative highlighting of ICT in education expertise is also assumed in this model. The emphasis placed here on intuitive spontaneity in handling multiple simultanous requirements is to draw out, in the extremity of this unusual contrast with physical education, some unexpected extras. These are that ICT expert quality supervision, while aiming to improve the supervisee's understanding and performance, also incorporates a holistic, selective and ultimately intuitive blend of those 'pedagogic' elements outlined in the 'four presence domains' - 'pedagogical, professional, commercial and managerial' - that Squires (1999) describes in his discussion of the role of peripatetic electronic teachers in higher education. In the context of Watson's (2001) emphasis that we should concentrate on pedagogy rather than the technocentric acquisition of skills (Papert, 1987), these elements can usefully be included within a hypothetical model for intuitive expertise in ICT graduate supervision. 


\section{Methodology}

As a personal reflection in the nature of a single-case study, this recollection of supervision forms the kind of 'critical' or 'unique case' outlined by Yin (1994) and Robson (1993). The unit for analysis in the study was the graduate supervision work carried out by one professorial supervisor with regard to master's and doctoral level supervision at King's College School of Education during the period 1990-9. The instance leading to this 'ex post facto' single-case reflection (Cohen, Manion and Morrison, 2000) - as opposed to a more normative multiple series of cases - was the untimely death of the supervisor, and the wish to record for posterity some successful elements of graduate supervision the supervisor had embodied. An analysis of the supervisory experience from the point of view of the supervisee was carried out. Relevant existing research on graduate supervision was taken into account, such as Heath's (2002) quantitative analysis of the views of 355 $\mathrm{Ph}$.D. candidates of their experience in supervision. The role of the graduate supervisor in the field of case-study research in computers in education relating to student composition in hypermedia, in particular, was considered.

A theorized model of intuitive expertise in ICT graduate supervision was therefore proposed, drawn from the supervision experience. This theoretical model was informed by prior research illustrating key aspects of the requirements for academic supervisors (Philips and Pugh, 1994) and for both coaches and mentors, as specified by professional sporting and performing arts researchers. An analytically generalizable theory of the role played by an 'expert ICT supervisor-coach-mentor' was outlined.

In view of the undoubted vulnerability of a single participant-observer reflection to bias and misrepresentation, this impressionistic study will be followed by an interrogation of the model by graduate students and key informants from King's College. This process will test the analytical generalizability and construct validity (Yin, 1994) of this very roughly sketched hypothesized model.

\section{The role of the graduate supervisor}

The role of the supervisor in postgraduate-level academic research study is of particular significance in the support of students. This sometimes unacknowledged fact is explored by both Phillips and Pugh (1994) and Blaxter, Hughes and Tight (1996), who cite nine expectations graduate students routinely have of supervisors, including constructively criticizing written work, being accessible, friendly, supportive, expert and informative in the subject area, and committed to supervisees' success. Phillips and Pugh (1994) also particularly note the role of supervisor as role model, and the essential underlying feature of good communication in the supervisor-supervisee interaction.

The supervisor-supervisee rapport can be of critical importance in fostering successful completion of students' written work. Some years ago, Kam (1997) confirmed this general recognition, evidenced by prior research in SERC (1982), Elliott (1983) and Bennett and Knibbs (1986), and noted that, 'very little attempt has been made to empirically examine the impact of this relationship on the quality of supervision'. Since Kam's own study on what he called 'the supervisory dependency factor' in graduate supervision relationships, however, there have been a number of studies evaluating supervisor-supervisee graduate supervision interaction. 
Fraser and Mathews (1999) widened out the traditional focus on subject expertise in the consideration of graduate supervisory interaction, by proposing a model including both student support and a balance of creativity with criticism in supervision. While Heath's more recent (2002) study of 355 Australian Ph.D. candidates found that the overwhelming majority ( 85 per cent) of supervisees expressed satisfaction with the expert knowledge of their supervisor(s), and 70-85 per cent noted satisfaction with a number of characteristics in supervision, not all studies of the supervisory relationship have focused on the supportive elements of what is generally recognized as a hierarchical relationship. Bartlett and Mercer (2000) note the combative elements within unequal power relations in graduate supervision, proposing an alternative familial model conceptualized from the point of view of experiential and feminist methodology.

In effect, such studies indicate that when the partnership between graduate supervisorsupervisee is problematic, the result can be student drop-out or non-completion. Chapman and Sork (2001) explore graduate supervision in adult higher education from the point of view of problematic power relations, and in their novel study refer particularly to the feminist vs. non-feminist debate in personal narrative methodology. Chapman and Sork describe a supervisor-supervisee relationship fraught with tensely observed complexities that achieves, uneasily, a useful - and inventive - mutual solution through joint publication.

Chapman and Sork's dialogue was informed by the five types of potential power relations between supervisor-supervisee outlined by Aguinis, Nesler, Quigley, Lee and Tedeschi (1996). 'Coercive', 'reward', 'legitimate', 'referent' and 'expert' power relations were identified in this analysis. The contribution of a perceptive and intuitive application of expertise in the supervisor-supervisee graduate research relationship is of particular relevance in this reflection on one successful experience of graduate supervision.

This is not necessarily the norm - significant problems with supervision can be so alarming to both students and supervisors as to cause depressing failures and student noncompletion. Experience of unproblematic expert collegiate graduate supervision may be much more routine than some of the literature on this subject would recently indicate, but perhaps successful processes of effective supervision can sometimes supply no overwhelming reasons for recording this success alongside the completion of already timeconstrained doctoral dissertations. A tendency, sometimes, to overlook - or even regard as automatic - the help provided by good supervisors in graduate study needs to be addressed. Supervision is not a transparently easy process, and this reflection is drawn up with that recognition in mind.

\section{Intuitive expertise in ICT graduate supervision}

The supervisee regarded Professor Squires' role as supervisor to be akin to that of an expert supervisor-coach-mentor. An academic combining friendliness with professional knowledge, seriousness of purpose, and an empathetic manner, the supervisee felt that Professor Squires instinctively inspired high levels of academic effort. A routine instance of this was that without fail, for every supervisory meeting throughout many years of part-time study at masters and doctoral level, the supervisor meticulously prepared commentary on the student's work and offered detailed advice on it, particularly challenging the supervisee to 
reach more advanced levels of understanding in her work. The application of discerning, simultaneously critical and creative analysis, was the norm for all supervision meetings for many years, negotiated through a professional, routinely updated learning contract.

An objective 'weighing up' process invariably accompanied this analysis, which in acknowledging current strengths and weaknesses and setting new intellectual goals, was somewhat similar to the measurement of an athlete's performance. An openness to the supervisee's own expert disciplinary knowledge in fields unknown to the supervisor was the norm. In bringing the focus back on the application of such disciplines to ICT in education, the challenge to concentrate on the timely achievement of deeper and more meaningful goals encouraged the supervisee to reach further, and aim higher, than previously ventured in any earlier studies.

The supervisee therefore began to conceptualize the graduate supervision process in ways comparable with the experience of a potential athlete being 'trained up' by an expert coach in sports or performing arts. The analogy of the expert physical education coach can be examined in relation to characteristics outlined by Ferguson and Jubenville (2001). These researchers cite the list of five 'Core Propositions' for effective sports teachers required by the National Board for Professional Teaching Standards (NBPTS, 2001), alongside expert coaching characteristics identified by DeMarco and McCullick (1997). Selected aspects of this work were mapped out and analysed in relation to the supervisee's experience of David Squires's supervision.

From a comparison of the NBPTS Standards (2001) and coaching characteristics identified by physical education researchers DeMarco and McCullick (1997), the supervisee drew up a list of traits for a proposed model of ICT supervision as expert coaching. These were examined in relation to key behavioural characteristics demonstrated in supervision during 1990-9. Six traits regarded as desirable for physical education coaches emerging directly from a combination of the NBPTS Standards (2001) and DeMarco and McCullick (1997) are the following:

- commitment to student learning;

- expert knowledge;

- superior problem-solving;

- instinctive mentoring;

- self-monitoring skills;

- participation in research culture.

In addition, the following traits were identified as particularly useful in relation to ICT in education. In this field, supervisees may face unusually challenging difficulties researching the interface between ICT, education, and other fields of subject-specific knowledge, such as English literature, or religious studies, and therefore the following abilities were specifically identified:

- intuitive expertise in facilitating students' own interdisciplinary problem-solving and advancement in new fields of knowledge;

- experiential insight into individual students' actual/potential cross-curricular capabilities in ICT in education; 
- innovative mentoring and brokering in supporting new interdisciplinary ICT student research activities.

Since the ICT graduate supervisor may be faced with a situation in which s/he may be required to supervise ICT supervisees with existing advanced knowledge in fields totally unknown to her/him, the role of intuition and imaginative support becomes crucial. The application of ICT cross-curricular graduate advanced studies to other subject disciplines is therefore decidedly challenging for supervisors. In the case of the present study, the supervisee's knowledge of English literature and media studies - which was to inform a major part of a thesis on the production of hypermedia compositions by further education students - was a case in point. In this field, the supervisor had little knowledge, and therefore needed to apply significant levels of imaginative effort to encompass the meaningfulness of the other disciplines to the supervisee's studies. Hence the analogy with physical education coaches draws attention to those aspects of supervisory skill that are beyond the planned cognitively specific application of subject knowledge. Fluency, adaptability and holistic spontaneity are required of the graduate supervisor to cope with this kind of advanced interdisciplinarity, especially at doctoral level.

In her discussion on the supervisory dialogues and strategies needed to support learning conversations between staff and students in doctoral supervision, Wisker (2002) reports on work done by Vilkinas (1998) refining Quinn's (1990) 'Dimensions of leadership' model of graduate supervision, which proposes eight roles for the supervisor. Vilkinas adds to these a ninth dimension - the integrator. The full nine characteristics identified in this comparison of a graduate supervisor with a manager are:

- mentor

- innovator

- broker

- producer

- director

- co-ordinator

- monitor

- facilitator

- with integration at the core of the whole (Wisker, 2002).

Essentially creative and visionary elements here in supervision are blended with managerial traits. Personally, I find this somewhat managerialist conception of supervision less invigorating than a more holistic model of the supervisor-coach-mentor, informed both by rigorous academic graduate supervisory standards and by professional physical education models of effective supervision. However, the role of 'integrator' provides a holism not present in the earlier Quinn model, and links more with the conception of intuitive expertise' envisaged in the ICT graduate supervision grid traced out in Figure 1.

In this grid, aspects of the Philips and Pugh (1994) comprehensive guide to Ph.D. supervision are placed side by side with selected key aspects of the NBPTS Professional 
Intuitive expertise in ICT graduate Phillips and Pugh (1994): students supervision model: characteristics of an expert supervisor

- committed to student learning

- well prepared

- available

- friendly

- supportive in mentoring

- open to discussion

- constructively critical

- challenging

- incisive

- effective in self-monitoring

- ICT-expert

- involved in research culture

- good record of academic work

- superior in problem-solving

- organized for tutorials

- open to debate

- informative

- interested in supervisee ideas

- influential with peers

- good networker

- committed to student success

AND:

- intuitive expertise in facilitating students' own interdisciplinary problem-solving and advancement in new fields of knowledge (expert teacher)

- experiential insight into individual students' actual/ potential cross-curricular capabilities in performance in ICT in education (coach)

- innovative mentoring and brokering for new interdisciplinary ICT research student activities (mentor)

- supervise them expect Ph.D. supervisors to:
- read their work in advance of a discussion

- be available when needed

- be friendly, open and supportive

- establish rapport

- be constructively critical

- self-monitoring skills

- instinctive mentor
NBPTS Professional Sporting Standard and De Marco and McCullick's (1997) characteristics of expert coach

- committed to student learning

- have a good knowledge of the research area

- expert knowledge

- superior problem-solving

- participation in research culture

- act as a role model

- structure the tutorial so that it is relatively easy to exchange ideas

- have sufficient interest in their research to put more information in the students' path, including introducing students to others in the field

- be sufficiently involved in their success to help them get a good job at the end of it all
- committed to student leaming

- committed to student leaming

- participation in research culture

Figure 1: Grid mapping different models of supervision/coach-mentoring against the concept of intuitive expertise in graduate $I C T$ supervision 
Sporting Standard and DeMarco and McCullick's (1997) characteristics of an expert coach. These are then mapped against desirable qualities in ICT expert graduate supervision, the broad aspects of each model being ranged against similar traits identified in the others. The aspects not explicitly replicated in the same manner elsewhere are ICTlinked concepts of: 1) intuitive expertise in facilitating student interdisciplinary problemsolving and knowledge advancement (expert teacher); 2) experiential insight into students' cross-curriculuar capabilities in performance (coach); and 3) innovative mentoring and brokering for new interdisciplinary ICT research student activities (mentor). It is these three aspects, therefore, to which I draw attention in considering the reinvigoration of pedagogical interdisciplinarity in ICT graduate supervisory experience. This is with particular reference to qualities of fluent holistic integration achieved in notable examples of the model of physical education coach-mentor.

\section{'Intuitive expertise' model of supervision}

In drawing out characteristics perhaps often assumed, but less routinely identified with graduate supervision, the model of intuitive expertise I propose encompasses also the dimensions of experiential insight and innovative mentoring. I argue that these are appropriate and timely additional aspects to consider in the reinvigoration of pedagogical conceptions of ICT called for by Watson, in her encouragement for educational computing to find its own voice, 'a philosophy, a rationale that is fundamentally societal and pedagogical' (Watson, 2001:264).

Given this need for the development - or, as some might see it - reawakening of the philosophy and rationale of ICT in education, I propose that these three additional characteristics in ICT graduate supervision, if added to the already given eleven characteristics derived from Philips and Pugh (1994) and Blaxter, Hughes and Tight (1996), provide important extra supervisory elements. Highlighting these elements of supervisory expertise, drawn more from models of coaching/mentoring in physical education than from prior academic role models, provides, in my view, a breath of fresh air in the somewhat dry atmosphere of well-worn academic conceptions of supervision.

The reason for this is that this conception focuses not solely on the intellectual and social characteristics routinely required in graduate supervision, nor on the technological knowledge assumed in ICT supervision, but on qualities associated with combinatory aspects of adaptive cognitive complexity, insight into individual students built up from experience and creativity in mentoring human inventiveness. I want to remind us here of Papert's definition of technocentric assumptions:

a tendency to reduce what are really the most important components of educational situations - people and cultures - to a secondary, facilitating role. The context for human development is always a culture, never an isolated technology. In the presence of computers, cultures might change and with them people's ways of learning and thinking. But if you want to understand (or influence) the change, you have to center your attention on the culture - not on the computer. (Papert, 1987)

Focusing our attention on human development, culture and pedagogy in ICT is not to forget the crucial role played by technological knowledge, but to enhance it. The role played by an expert academic as supervisor-coach-mentor in this iterative process of 


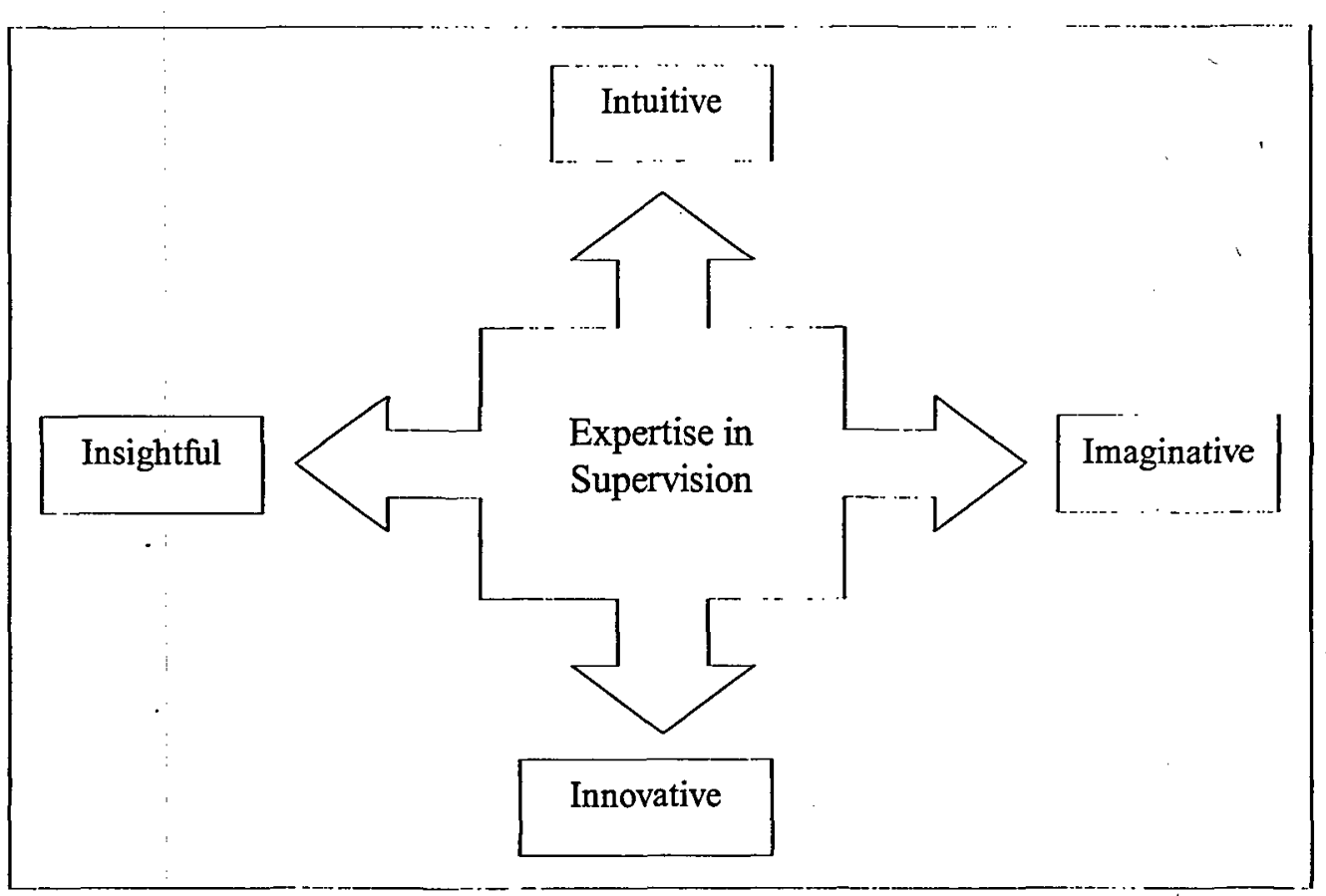

Figure 2: Model for intuitive expertise in ICT graduate supervision

enhancing knowledge and learning is subtle. A fine holistic balance of the traits of academic supervision and coaching/mentoring needs to be applied. In this, the expert supervisor knows his/her students' potential, and encourages them to achieve the maximum they can within available resources and time.

Delivering truthful criticism within an overall supportive learning environment is a difficult balance to achieve. In addition to expert knowledge and commitment to the student, the expert supervisor-coach-mentor therefore needs the kind of complex range of skills identified in good teaching in the models outlined above, such as good human communication, problem-solving, instinctive understanding and interactional skills. If both supervisor and supervisee are genuinely committed to the achievement of success in specialist research within a framework enabled by the coaching/mentoring environment outlined, then difficult issues over subject discipline and personality differences are likely to be well handled. Professional differences in subject knowledge and critical comment become no longer directed at the person, but at the work itself, just as in effective sports coaching, many improvements can be effectively and successfully demanded in a training regime within a trusting atmosphere. When trust in the supervisor-supervisee relationship is established, it becomes possible to be fundamentally and radically critical about the work without the other person taking offence. Constructive criticism of both intradisciplinary differences and the supervisor's style by the supervisee should also be delivered effectively within such a framework. Overall, a useful working balance of intellectual and affective elements can result in supervision perceived by both parties to be effective. 


\section{Conclusion}

The model of intuitive expertise in ICT graduate supervision outlined here examines a holistic rounded view of the supervisor-supervisee experience in supervision, considering a range of supervisory characteristics in the concept of expertise. These focus not merely on intellectual capability and depth of knowledge, but encompass a holistic blend of affective, social, communicative and other areas of advanced skill not always routinely conceptualized as part of supervision. Three new characteristics in ICT graduate supervision are proposed, building on already-given qualities in prior models of graduate supervision. Attributes of effective coach-mentors in professional physical education are placed alongside these in a grid and examined in relation to the proposed model for ICT supervision. In the author's experience, Professor David Squires demonstrated advanced capabilities as a supervisor derived from the kind of matrix of complex supervisory characteristics outlined and visually sketched in the concept of supervision as intuitive expertise. This small single-case reflective analysis aims to capture a brief portrait of some of these elements, to contribute to the literature on effective graduate supervision for the benefit of future supervisors and students. Merely a transitory ex post facto memorial reflection, the model sketched here is drawn up in an awareness of the multiple potential flaws inherent in a subjective single-case participant-observer attempt to capture some useful elements of supervision that will be tested with key informants in the future.

\section{Acknowledgements}

The author wishes to acknowledge David Squires himself for the work done throughout many years of graduate supervision. Acknowledgements are gratefully given to Kevin and Imogen for their patience and support in the writing of this paper.

\section{References}

Aguinis, H., Nesler, M. S., Quigley, B. M., Lee, S. and Tedeschi, J. T. (1996), 'Power bases of faculty supervisors and educational outcomes for graduate students', Journal of Higher Education, 67, 267-97.

Ainley, P., Jameson, J., Jones, P., Hall, D. and Farr, M. (2002), 'Redefining higher education: a case study in widening participation', in A. Hayton and A. Pazuska, Widening Participation in Higher Education, London: Institute of Education.

Bartlett, A. and Mercer, G. (2000), 'Reconceptualising discourses of power in postgraduate pedagogies', Teaching in Higher Education, 5 (2), 195-204.

Bennett, R. and Knibbs, J. (1986), 'Researching for a higher degree: the role(s) of the supervisor', Management Education and Development, 17 (2), 137-45.

Blaxter, L., Hughes, C., and Tight, M. (1996), How to Research, Buckingham: Open University Press.

Chapman, V. and Sork, T. J. (2001), 'Confessing regulation or telling secrets? Opening up the conversation on graduate supervision', Adult Education Quarterly, 51 (2), 94-107.

Cohen, L., Manion, L. and Morrison, K. (2000), Research Methods in Education, London: Routledge/Falmer, 206-10. 
DeMarco, G. M. and McCullick, B. A. (1997), 'Developing expertise in coaching: learning from the legends', Journal of Physical Education Recreation and Dance, 68, (3), 37-41.

Elliott, K. (1983), 'Journey to an unknown destination: a letter to a research student', Graduate Management Research, 1 (1), 6-11.

Ferguson, J. and Jubenville, C. (2001), 'Coaching, teaching, and critiquing!', Sportopalis newsletter on-line column: The New'P.E. and Sports Dimension, No 2, July, http:/lwww.sports-media.org/Sportapolisnewsletter3.htm.

Fraser, R. W. and Mathews, A. (1999), 'An evaluation of the desirable characteristics of a supervisor', Australian Universities' Review, 42 (1), 5-7.

Hartley, R. (2001), 'Review of E. Parsloe and M. Wray, coaching and mentoring practical methods to improve learning', $A L T-J, 9$ (3), 78-9.

Heath, T. (2002), 'A quantitative analysis of $\mathrm{PhD}$ students' views of supervision', Higher Education Research and Development, 21 (1), 41-52.

Jameson, J. (1999), 'The development of an explanatory model and assessment instrument to evaluate the production of hypermedia compositions by further education students', University of London King's College, School of Education Ph.D. thesis.

Jameson, J. and Squires, D. (2000), 'Teaching new media composition studies in a lifelong learning context', ALT-J, 8 (3), 41-55.

Kahn, T. M. and Ullah, L. K. T. (1997), 'Learning by design: integrating technology into the curriculum through student multimedia design projects', New Horizons for Learning.

Kam, B. H. (1997), 'Style and quality in research: the supervisor dependency factor', Higher Education, 34, 81-103.

National Board for Professional Teaching Standards (2001), The Five Propositions of Accomplished Teaching [online]. Available: http://www.nbpts.org

Papert, S. (1987), 'Computer criticism vs. technocentric thinking', Educational Researcher, $16(1), 22-30$.

Papert, S. (1991), 'Situating constructionism', in I. Harel and S. Papert (eds.), Constructionism, Norwood, NJ: Ablex Publishing Corporation, 1-12.

Parsloe, E. and Wray, M. (2000), Coaching and Mentoring: Practical Methods to Improve Learning, London: Kogan Page.

Philips, E. M., and Pugh, D. S. (1994), How to get a PhD: A Handbook for Students and their Supervisors, Milton Keynes: Open University.

Quinn, R. E., Faerman, S. R., Thompson, M. P. and McGrath, M. R. (1990), Becoming a Master Manager. A Competency Framework, New York: John Wiley \& Sons.

Robson, C. (1993), Real World Research: A Resource for Social Scientists and PractitionerResearchers, Oxford, Blackwell.

Salomon, G., Perkins, D. and Globerson, T. (1991), 'Partners in cognition: extending human intelligence with intelligent technologies', Educational Reseacher, 20 (4), 2-9. 
SERC (1982), Research Student or Supervisor - A Discussion Document in Good Supervisory Practice, London: Science and Engineering Research Council.

Squires, D. (1999), 'Peripatetic electronic teachers in higher education', ALT-J, 7 (3), 52-63.

Stemler, L. K. (1997), 'Educational characteristics of multimedia: a literature review', Journal of Educational Multimedia and Hypermedia, 6 (3/4), 339-60.

Tan, S. (1997), 'The elements of expertise', Journal of Physical Education, Recreation and Dance, 68 (2), 30-3.

Tharp, R. and Gallimore, R. (1976), 'What a coach can teach a teacher', Psychology Today, January, 75-8.

Thompson, A., Handsen, D. and Reinhart, R. (1996), 'One-on-one technology mentoring for teacher education faculty: case study reports', in B. Robin, J. D. Price, J. Wills and D. A. Willis (eds.), Technology and Teacher Education Annual, 1996, Proceedings of SITE 1996, AACE, Phoenix, AZ, 495-8.

Vilkinas, T. (1998), 'Management of the PhD process: the challenging role of the supervisor', in M. Kiley and G. Mullins (eds), Quality in Postgraduate Research, Adelaide: University of Adelaide.

Watson, D. M. (2001), 'Pedagogy before technology: re-thinking the relationship between ICT and teaching', Education and Information Technologies, 6 (4), 251-66.

Wisker, G. (2002), 'From supervisory dialogues to successful PhDs: strategies supporting and enabling the learning conversations of staff and students at postgraduate level', Proceedings of the Annual International Conference of the Higher Education Research and Development Society of Australasia, Perth: HERSDA.

Yin, R. K. (1994), Case Study Research: Design and Methods, 2nd edn, Applied Social Research Methods Series 5, London: Sage Publications, Inc. 